\title{
The validity of an area-based method to estimate the size of hard-to-reach populations using satellite images: the example of fishing populations of Lake Victoria
}

Stephen Nash ${ }^{1 *}$ (D) Victoria Tittle ${ }^{1}$, Andrew Abaasa ${ }^{2}$, Richard E. Sanya ${ }^{2}$, Gershim Asiki ${ }^{2}$, Christian Holm Hansen ${ }^{1,2}$, Heiner Grosskurth ${ }^{1,3}$, Saidi Kapiga ${ }^{1,3}$ and Chris Grundy ${ }^{1}$ on behalf of Lake Victoria Consortium for Health Research

\begin{abstract}
Background: Information on the size of populations is crucial for planning of service and resource allocation to communities in need of health interventions. In resource limited settings, reliable census data are often not available. Using publicly available Google Earth Pro and available local household survey data from fishing communities (FC) on Lake Victoria in Uganda, we compared two simple methods (using average population density) and one simple linear regression model to estimate populations of small rural FC in Uganda. We split the dataset into two sections; one to obtain parameters and one to test the validity of the models.

Results: Out of 66 FC, we were able to estimate populations for 47. There were 16 FC in the test set. The estimates for total population from all three methods were similar, with errors less than 2.2\%. Estimates of individual FC populations were more widely discrepant.

Conclusions: In our rural Ugandan setting, it was possible to use a simple area based model to get reasonable estimates of total population. However, there were often large errors in estimates for individual villages.
\end{abstract}

\section{Background}

Knowing the size of a population is vital to many aspects of public health [1-3] including intervention planning and resource allocation [4]. Population census data are often used to provide this information, but this method is expensive and time-intensive even for small areas [5]. There are also limitations of this method due to population mobility and the time that may have elapsed since a census was conducted [5]. In low-resource settings these limitations are often particularly acute, and so other methods are needed to estimate population sizes $[4,6]$.

\footnotetext{
*Correspondence: Stephen.Nash@lshtm.ac.uk

${ }^{1}$ London School of Hygiene and Tropical Medicine, Room G13, Keppel

Street, London WC1E 7HT, UK

Full list of author information is available at the end of the article
}

Satellite imagery has been used for population estimates since the 1950s, utilising spectral and spatial satellite data to determine land use for statistical modelling [7]. The use of this technology has grown rapidly since 2005 as high resolution images became widely accessible, increasing access to images of rural settings around the world [3].

There are a number of different ways to estimate the population size of a community from satellite images of the area. One way involves counting structures seen in the images, a method that has been tested in many settings, using both manual counting and automated counts [8]. Comparison of estimates from this method to reference population counts show varying results depending on image quality, particularly regarding their ability to distinguish between individual structures $[8,9]$. In locations with clearly visible structures 
and a reliable estimate of average population per structure for that region, it is possible to estimate population size by simply multiplying the number of structures by the average occupancy per structure. Such estimates, from both manual and automated counts of structures, are typically within a few percent of the results from a survey of the same location [8]. Organisations such as UNHCR, Médecins Sans Frontières, and the International Federation of Red Cross and Red Crescent Societies routinely use this method to estimate size of populations.

The structure-based method is particularly suitable when only a small area is being studied. While crowdsourcing from groups like Missing Maps or Humanitarian OpenStreetMap Team (HOT) use large numbers of volunteers to cover large land areas $[10,11]$ there are still inherent problems with this method when image quality is poor or out of date; where individual structures cannot be seen; or where the mobilisation of sufficient numbers of volunteers is a challenge.

An alternative approach is to use the area of a village, rather than the number of buildings. Estimating the area of a village doesn't rely on such high resolution satellite images as is required to count individual structures, and is also quicker to do using straightforward geographical software. Hence, if a reliable estimate of population density was available for a particular geographical region, it is possible to estimate population size simply by multiplying this population density by the area of the region of interest.

The aim of this paper is to establish if there is indeed an average population density figure which can be used to produce reasonable estimates of population size for rural villages. We will use known population data from fishing communities on or near the shores of Lake Victoria in Uganda. We will use two thirds of the villages to produce an estimate of population density, which we will then use to produce population estimates for the remaining villages. We will also present the overall population density of all villages, in the hope that this figure can be used and tested by other researchers working in East Africa. An open question is in which locations and settings will it be reasonable to use this average population density to estimate populations.

We also explore whether the simple model of "density times area" described above works as well as more complicated, but still straightforward to implement, regression models. We investigate if these methods provide reasonable population estimates of both the overall area and of individual villages.

Our hope is that the methods explored here will allow a reasonable population estimate to be produced at low cost in terms of time and resources, and that the estimates will be of sufficient accuracy for use in situations where census data are unavailable.

\section{Methods \\ Setting}

We use data from the fishing communities of Lake Victoria in Uganda. The villages were selected as already having been surveyed in previous research by the research teams from the MRC/UVRI Uganda Research Unit and therefore accurate population data and global positioning system (GPS) location for each village were available. All estimates obtained from the methods described below were compared to these ground survey data. A fishing community (FC) was defined as a residential area in which the majority of the residents rely on Lake Victoria for income generation. Household surveys were conducted in 2012-13 and counted number of households and number of people in each household [12, 13]. All of the villages are fishing communities, with 39 on the mainland and 27 on the islands of Lake Victoria. These communities are characterised by single storey buildings, with the majority used for residential purposes. These communities are hard-to-reach, poorly served by skilled health care providers and have poor access to clean water and sanitation. Health issues include HIV, helminth infection, malaria, and high maternal and newborn morbidity. The populations of these communities are typically very mobile, consisting of transient populations who move between villages and within the wider region and country.

Each community was viewed in Google Earth Pro software (GEP) and communities with no central cluster of residential structures were excluded. We also excluded fishing communities for which GPS coordinates did not show up as a village on the available satellite imagery, or where satellite images were unavailable.

\section{Estimation of area using GEP}

For each fishing community with satellite imagery available, we used GEP software to assess the area as follows. A member of our team [CG] estimated the perimeter of each community based on where structures were observable, and assessed density as either low or high, based on the space visible between structures on the satellite image (see Fig. 1). Although the perimeter was drawn so as to enclose the majority of structures which naturally formed the community, it was occasionally the case that some structures were excluded. The area enclosed within the perimeter was calculated automatically by the GEP software. We estimate that this process took less than 1 min per FC. 

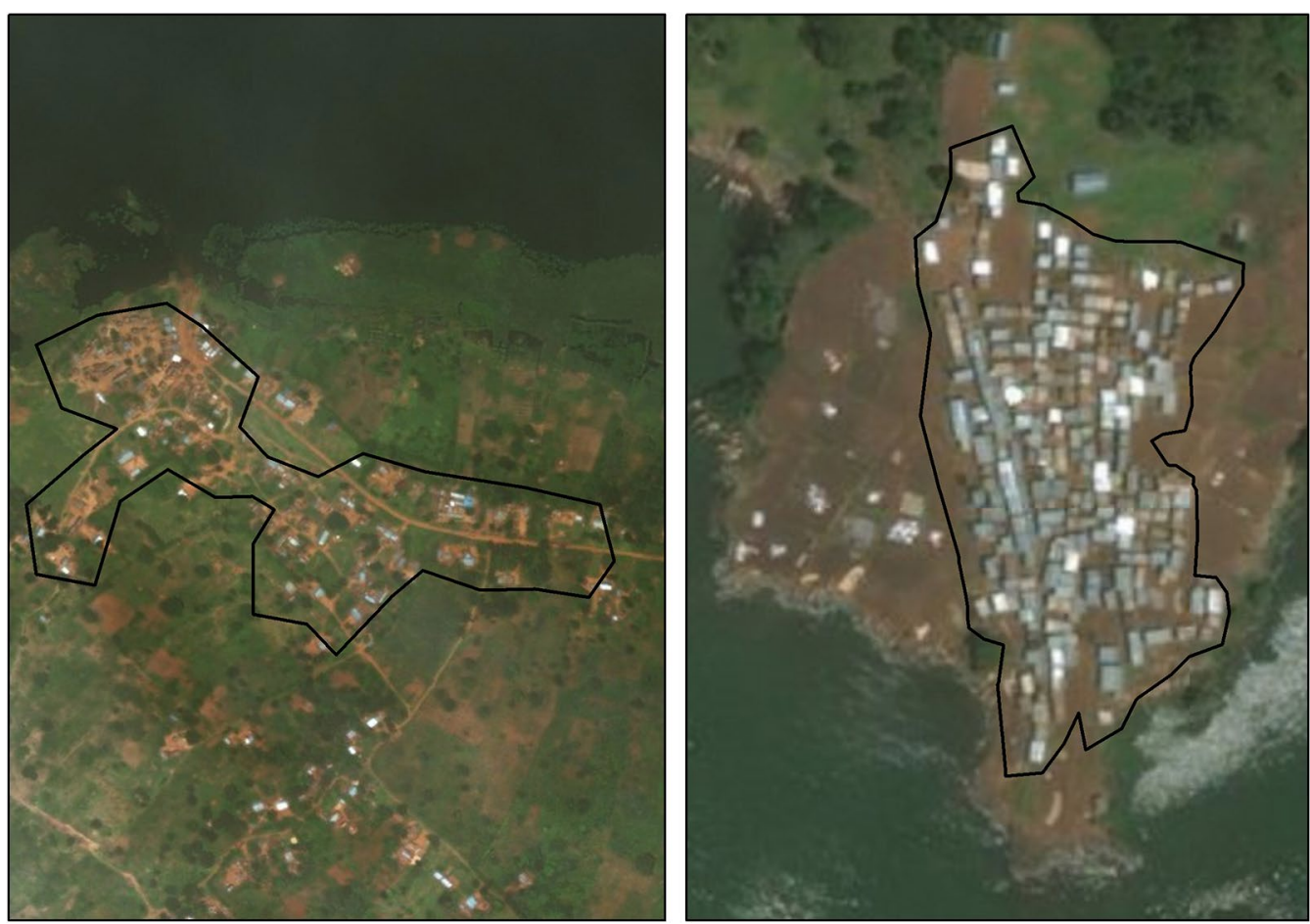

Fig. 1 Examples of boundaries fitted to the typical satellite images of FC

\section{Estimation of populations}

We compared three methods of estimating populations: two using the average density and one using a regression model. The two average density methods calculated the average in different ways: the first used the average of the individual FC densities; the second used the overall population density calculated by summing the population of all FCs and dividing by the total area. We refer to these two methods as AD1 and AD2. The simple linear regression model we used consisted of a constant term and the FC area as the single predictor. The average density methods can be considered as regression models without a constant term; this allows the first two methods to be described as:

$$
Y_{i}=\beta \times \text { area }_{i}
$$

where $Y_{i}$ is the predicted population for village $i$, and $\beta$ is the average population density (however calculated). The regression method can be described as

$$
\mathrm{Y}_{\mathrm{i}}=\alpha^{*}+\beta^{*} \times \text { area }_{\mathrm{i}}
$$

where $\alpha^{*}$ and $\beta^{*}$ are the regression coefficients representing the intercept and slope respectively. All population estimates are presented rounded to the nearest whole number; when calculating total populations by summing individual populations the original estimates were used.
To allow us to test and compare these approaches we randomly split the data into two sets: an index set of 31 FCs which we used to calculate the parameters (average density and regression coefficients) and a test set of 16 FCs which we used to compare the predictions made by these parameters with the values from the earlier surveys. We also calculated the unstratified parameters in the entire dataset of $47 \mathrm{FC}$ 's, as these are the best available estimates from the data we have. We report each of these parameters with a $95 \%$ confidence interval (CI), with the exception of the M2 parameter for which a $\mathrm{CI}$ cannot be calculated as it is the simple ratio of total population to total area.

\section{Average density methods}

To calculate the average density of FC for M1 we first calculated the density in each of the 31 index FCs and then used the mean of these figures as the parameter $\beta_{\mathrm{M} 1}$. We then applied this value to each of the 16 test FCs to predict their population, and summed these estimates to give a total population for the test FCs. For M2 we calculated the total population of the 31 index communities and divided by their total area, and again used this parameter $\beta_{\mathrm{M} 2}$ to calculate the populations of the remaining FC. 


\section{Regression method}

We ran a simple linear regression, using area as a predictor of population, on the 31 index FCs. We took the parameters from this regression ( $\alpha^{*}$, the intercept and $\beta^{*}$, the coefficient for area) applied them to the 16 test FCs. We summed these individual estimates to get an estimate for the total population of the 16 test FCs. Note that because the constant is calculated at the village level, it was not possible to apply these parameters to an entire region; they must be applied at the village level.

\section{Stratifying by location and density}

We repeated the above twice: once stratifying on location (island/mainland) and once stratified on assessed density category (low/high). In each case, we used the same original set of index and test FC, to enable comparison between the methods. We then separately calculated parameters in each stratum, and applied them to the test FC according to stratification level. This is equivalent to allowing an interaction between area and the stratification factor in Eqs. 1 and 2; alternatively it can simply be expressed as separate equations with equivalent parameters for each level of the stratification factor. That is, parameters $\beta_{\text {island }} \beta_{\text {mainland }} \beta_{\text {low-density, }}$ and $\beta_{\text {high-density }}$, and similarly for $\beta^{*}, \alpha$ and $\alpha^{*}$.
Stata v15.0 was used for population estimation and GEP was used to obtain satellite images and estimate areas.

\section{Results}

We had population data on 66 FCs. Of these, eight were excluded due to absence of satellite imagery, nine due to no village being visible on the satellite image and one due to no GPS coordinate for the population data.

The analysis presented here was conducted on $47 \mathrm{FCs}$ (see map, Fig. 2). The total population from surveys was 29,574 . The combined area was $1,030,918 \mathrm{~m}^{2}$, giving an overall average population density of 0.0293 people per $\mathrm{m}^{2}$. The mean of the individual densities across the 47 communities was 0.0287 people per $\mathrm{m}^{2}$. The mean FC population was 629 , but there was large variation among the individual communities (Table 1). The range in FC population was from 99 to 3134, with a standard deviation of 616 . The population density ranged from 0.008 to 0.064 per $\mathrm{m}^{2}$, with a standard deviation (SD) of 0.012 . Twenty-six communities were situated on islands; with the remainder on the mainland. The mean of individual population densities were 0.0319 and 0.0260 per $\mathrm{m}^{2}$ for island and mainland FC respectively. The overall average population density was 0.0306 on islands and 0.0270 on

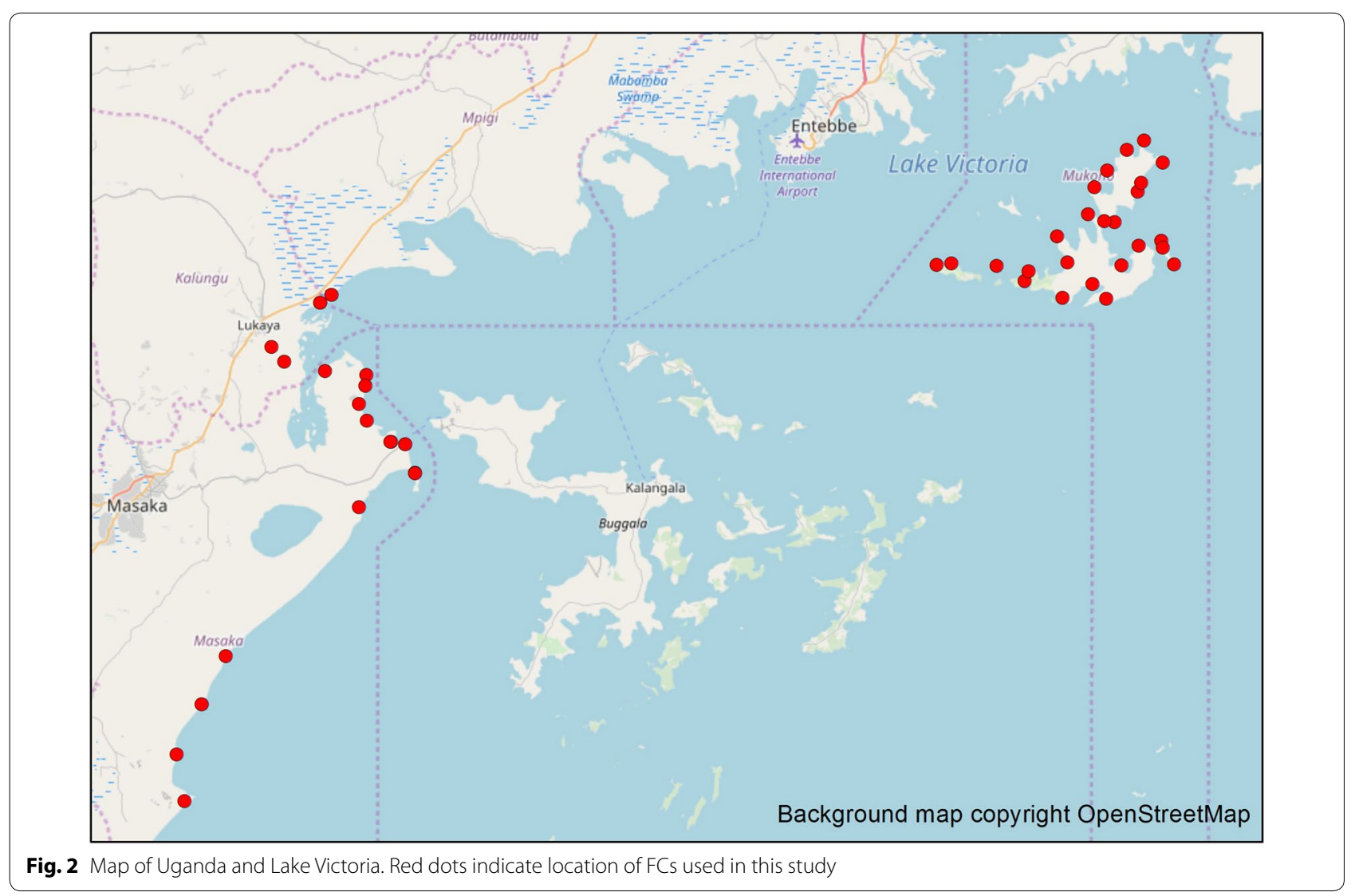


Table 1 Characteristics of fishing communities

\begin{tabular}{|c|c|c|c|c|c|c|c|c|c|}
\hline Id & Name & Mainland & $\begin{array}{l}\text { Assessed } \\
\text { density }\end{array}$ & Population & Area $\left(m^{2}\right)$ & Density & Index & Date of survey & Date of image \\
\hline 1 & Kibanga & Island & Low & 189 & 7517 & 0.0251 & Index & October 2012-July 2013 & $11 / 10 / 2014$ \\
\hline 2 & Bbaale & Island & Low & 240 & 13,456 & 0.0178 & Index & October 2012-July 2013 & 07/07/2013 \\
\hline 3 & Zingoola & Island & Low & 670 & 32,696 & 0.0205 & Index & October 2012-July 2013 & $11 / 10 / 2014$ \\
\hline 4 & Busi & Island & High & 166 & 5502 & 0.0302 & Index & October 2012-July 2013 & $11 / 10 / 2014$ \\
\hline 5 & Busiro & Island & High & 209 & 6880 & 0.0304 & Index & October 2012-July 2013 & $27 / 02 / 2015$ \\
\hline 6 & Muga-Ngogo & Island & High & 261 & 9635 & 0.0271 & Index & October 2012-July 2013 & $11 / 10 / 2014$ \\
\hline 7 & Tabaliro & Island & High & 271 & 5144 & 0.0527 & Index & October 2012-July 2013 & 08/01/2015 \\
\hline 8 & Nambu & Island & High & 308 & 11,726 & 0.0263 & Index & October 2012-July 2013 & $27 / 02 / 2015$ \\
\hline 9 & Katooke & Island & High & 340 & 11,588 & 0.0293 & Index & October 2012-July 2013 & $27 / 02 / 2015$ \\
\hline 10 & Kachanga & Island & High & 403 & 13,151 & 0.0306 & Index & October 2012-July 2013 & $27 / 02 / 2015$ \\
\hline 11 & Lubembe & Island & High & 641 & 22,531 & 0.0284 & Index & October 2012-July 2013 & $11 / 10 / 2014$ \\
\hline 12 & Mwoma & Island & High & 654 & 19,883 & 0.0329 & Index & October 2012-July 2013 & $11 / 10 / 2014$ \\
\hline 13 & Kitosi & Island & High & 660 & 24,861 & 0.0265 & Index & October 2012-July 2013 & $11 / 10 / 2014$ \\
\hline 14 & Kakeeka & Island & High & 668 & 13,441 & 0.0497 & Index & October 2012-July 2013 & $11 / 10 / 2014$ \\
\hline 15 & Misenyi & Island & High & 734 & 40,065 & 0.0183 & Index & October 2012-July 2013 & $11 / 10 / 2014$ \\
\hline 16 & Myenda & Island & High & 780 & 22,208 & 0.0351 & Index & October 2012-July 2013 & $11 / 10 / 2014$ \\
\hline 17 & Kiimi & Island & High & 1557 & 44,725 & 0.0348 & Index & October 2012-July 2013 & $11 / 10 / 2014$ \\
\hline 18 & Kalyambuzi & Island & High & 1560 & 34,577 & 0.0451 & Index & October 2012-July 2013 & $27 / 02 / 2015$ \\
\hline 19 & Kansambwe & Island & High & 1685 & 55,858 & 0.0302 & Index & October 2012-July 2013 & 08/01/2015 \\
\hline 20 & Buzirango & Mainland & Low & 99 & 3910 & 0.0253 & Index & March 2013-May 2013 & $17 / 01 / 2012$ \\
\hline 21 & Kamaliba & Mainland & Low & 168 & 20,371 & 0.0082 & Index & March 2013-May 2013 & $13 / 08 / 2012$ \\
\hline 22 & Bbale & Mainland & Low & 194 & 12,539 & 0.0155 & Index & March 2013-May 2013 & $17 / 01 / 2012$ \\
\hline 23 & Kabasese & Mainland & Low & 340 & 10,060 & 0.0338 & Index & March 2013-May 2013 & $17 / 01 / 2012$ \\
\hline 24 & Mitondo & Mainland & Low & 359 & 17,639 & 0.0204 & Index & March 2013-May 2013 & $17 / 01 / 2012$ \\
\hline 25 & Kamunga & Mainland & Low & 403 & 43,141 & 0.0093 & Index & March 2013-May 2013 & $13 / 08 / 2012$ \\
\hline 26 & Kachanga & Mainland & Low & 491 & 23,123 & 0.0212 & Index & March 2013-May 2013 & $25 / 11 / 2008$ \\
\hline 27 & Kaziru & Mainland & Low & 892 & 54,227 & 0.0164 & Index & March 2013-May 2013 & $17 / 01 / 2012$ \\
\hline 28 & Makonzi & Mainland & High & 306 & 7572 & 0.0404 & Index & March 2013-May 2013 & $17 / 01 / 2012$ \\
\hline 29 & Kabasese & Mainland & High & 369 & 11,376 & 0.0324 & Index & March 2013-May 2013 & $13 / 08 / 2012$ \\
\hline 30 & Kachanga & Mainland & High & 599 & 23,957 & 0.0250 & Index & March 2013-May 2013 & $17 / 01 / 2012$ \\
\hline 31 & Lambu & Mainland & High & 3134 & 48,875 & 0.0641 & Index & March 2013-May 2013 & $25 / 11 / 2008$ \\
\hline 32 & Lwanga Muto & Island & Low & 208 & 7367 & 0.0282 & Test & October 2012-July 2013 & $11 / 10 / 2014$ \\
\hline 33 & Kisigala & Island & Low & 535 & 14,474 & 0.0370 & Test & October 2012-July 2013 & $11 / 10 / 2014$ \\
\hline 34 & Maala & Island & High & 250 & 7564 & 0.0331 & Test & October 2012-July 2013 & 02/02/2015 \\
\hline 35 & Kayunyu & Island & High & 287 & 14,439 & 0.0199 & Test & October 2012-July 2013 & $11 / 10 / 2014$ \\
\hline 36 & Batwala & Island & High & 399 & 7072 & 0.0564 & Test & October 2012-July 2013 & 27/01/2015 \\
\hline 37 & Lugumba & Island & High & 446 & 22,574 & 0.0198 & Test & October 2012-July 2013 & $11 / 10 / 2014$ \\
\hline 38 & Kisso & Island & High & 710 & 15,986 & 0.0444 & Test & October 2012-July 2013 & 27/02/2015 \\
\hline 39 & Kalangala & Mainland & Low & 108 & 4167 & 0.0259 & Test & March 2013-May 2013 & 17/01/2012 \\
\hline 40 & Kamaliba & Mainland & Low & 190 & 18,497 & 0.0103 & Test & March 2013-May 2013 & $13 / 08 / 2012$ \\
\hline 41 & Kassa & Mainland & Low & 262 & 7316 & 0.0358 & Test & March 2013-May 2013 & $17 / 01 / 2012$ \\
\hline 42 & Kalokoso & Mainland & Low & 295 & 15,313 & 0.0193 & Test & March 2013-May 2013 & 07/07/2013 \\
\hline 43 & Kisuku & Mainland & Low & 553 & 21,424 & 0.0258 & Test & March 2013-May 2013 & $17 / 01 / 2012$ \\
\hline 44 & Namirembe & Mainland & Low & 619 & 28,004 & 0.0221 & Test & March 2013-May 2013 & $22 / 12 / 2009$ \\
\hline 45 & Kamuwunga & Mainland & Low & 1313 & 44,771 & 0.0293 & Test & March 2013-May 2013 & $13 / 08 / 2012$ \\
\hline 46 & Ddimo & Mainland & Low & 1645 & 74,668 & 0.0220 & Test & March 2013-May 2013 & 07/07/2013 \\
\hline 47 & Lambu & Mainland & High & 2404 & 55,048 & 0.0437 & Test & March 2013-May 2013 & $25 / 11 / 2008$ \\
\hline
\end{tabular}




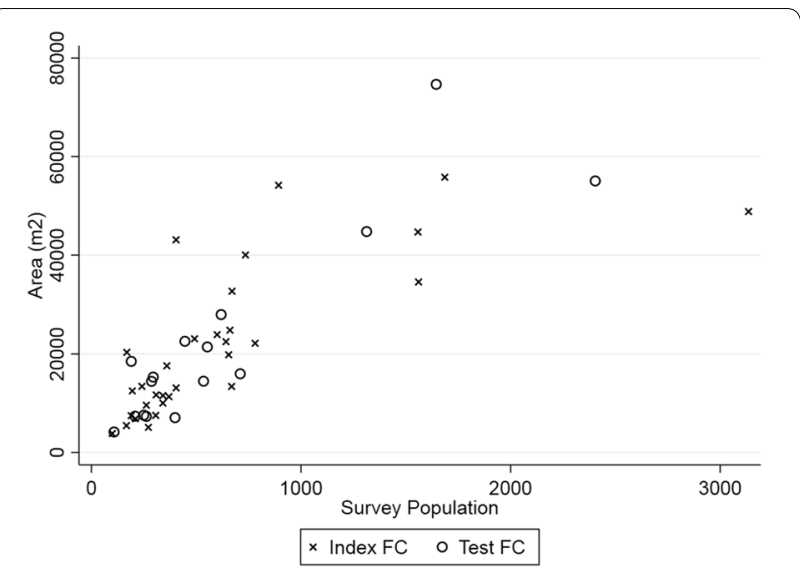

Fig. 3 Plot of area against survey population for each FC

the mainland. A plot of area against survey population is shown in Fig. 3.

We assessed 21 FCs as low density and 26 as high density. Of the 21 assessed as low density, the actual density calculated from the survey population ranged from 0.008 to 0.037 , with a mean of 0.0224 per $\mathrm{m}^{2}$. The overall average population density was 0.0206 per $^{2}$. For those FCs assessed as high density, the actual density ranged from 0.018 to 0.064 with a mean of 0.0348 . The overall average population density was 0.0356 per $^{2}$. Of the $21 \mathrm{FCs}$ with lowest actual density, we assessed 16 (correctly) as low density and five (incorrectly) as high density. One possible explanation for this misclassification is the amount of time between the survey and the satellite image.

The 31 FCs assigned to the index set had an overall population of 19350 and a total area of $672234 \mathrm{~m}^{2}$. The equivalent figures for the 16 test FCs were 10224 and $358684 \mathrm{~m}^{2}$.

\section{Parameter estimates}

The average density of the 31 index FCs was $\beta_{\mathrm{M} 1}=0.0291$ per $\mathrm{m}^{2}$. The overall average population density was $\beta_{\mathrm{M} 2}=0.0288$. The regression parameters were $\beta^{*}=0.0302$ for the slope and $\alpha^{*}=-30.36$ for the constant. In the entire dataset of $47 \mathrm{FC}$ 's the M1 parameter was 0.0293 , with a $95 \% \mathrm{CI}$ of $(0.025,0.0328)$. The M2 parameter was 0.0287 . The regression parameters in the complete dataset were $\alpha=-13.32$, with a $95 \%$ CI of $(-198.86,172.22)$ and $\beta=0.0293,95 \% \mathrm{CI}(0.0225,0.0361)$. All other regression parameters are shown in Table 2.

\section{Total population}

The average density method M1 predicted a total population of the 16 test FC of 10452, an overestimate of 228 (2.2\%) compared to the census data. Method M2 predicted a total population of 10325, also an overestimate,
Table 2 Parameters from estimation methods

\begin{tabular}{|c|c|c|c|c|}
\hline \multirow{2}{*}{$\begin{array}{l}\text { Method } \\
\text { Parameter }\end{array}$} & \multirow{2}{*}{$\begin{array}{l}\text { M1 } \\
\text { Beta }\end{array}$} & \multirow{2}{*}{$\begin{array}{l}\text { M2 } \\
\text { Beta }\end{array}$} & \multicolumn{2}{|l|}{ Regression } \\
\hline & & & Alpha & Beta \\
\hline All FC's & 0.0293 & 0.0287 & -13.3193 & 0.0293 \\
\hline $95 \% \mathrm{Cl}$ & $\begin{array}{c}(0.0258 \\
0.0328)\end{array}$ & - & $\begin{array}{c}(-198.86 \\
172.22)\end{array}$ & $(0.0225,0.0361)$ \\
\hline \multicolumn{5}{|c|}{ Index FC's only } \\
\hline All index FC's & 0.0291 & 0.0288 & -30.3628 & 0.0302 \\
\hline Low density & 0.0194 & 0.0194 & 86.8760 & 0.0129 \\
\hline High density & 0.0345 & 0.0345 & -93.6135 & 0.0396 \\
\hline Island & 0.0311 & 0.0303 & 16.5572 & 0.0295 \\
\hline Mainland & 0.0260 & 0.0266 & -112.4567 & 0.0314 \\
\hline
\end{tabular}

of $101(0.99 \%)$. The regression method predicted a total population of 10341, an overestimate of 117 (1.1\%).

\section{Individual FC populations}

Using method M1, the largest absolute discrepancy of an individual FC population was 800 (FC \#47; population 2404; estimated population 1604). The same FC also produced the largest error from the other two methods: M2 predicted 1585 (discrepancy $=819$ ) and the regression method predicted 1631 (discrepancy $=773$ ). The largest relative discrepancy for all three methods was with the FC \#40, which has a survey population of 190. Using M1, our prediction was 539 (83.7\% overestimate), using M2 it was 532 (80.0\% overestimate) and using the regression method it was 528 (77.9\% overestimate). Full results are shown in Table 3.

\section{Stratification by location}

Stratifying by location did not improve the overall estimates of the average density methods, but did improve the regression method. The estimated overall population using M1 was 9788, an underestimate of 436 (4.3\%); using M2 the estimate was 9867, an underestimate of 357 (3.5\%); and using the regression method the estimate was 10212, an underestimate of just $0.12 \%$. Full results for individual FC population estimates are shown in Table 4. The largest discrepancies again occurred in predictions of FC \#47 (absolute error) and FC \#40 (relative error).

\section{Stratifying by assessed density category}

Using method M1 stratified by assessed density, the overall population estimate was 8815 , compared to a survey population of 10224. This is an underestimate of 1409 (13.8\%). Using method M2 produced an estimate of 8330, an underestimate of 1894 (18.5\%); the regression method fared worse with a population estimate of 8222 , 
Table 3 Estimates of individual FC populations from all methods

\begin{tabular}{|c|c|c|c|c|c|c|c|c|c|c|}
\hline \multirow[t]{2}{*}{ Id } & \multirow[t]{2}{*}{ Name } & \multicolumn{3}{|c|}{ Population estimates } & \multicolumn{3}{|c|}{ Discrepancy } & \multicolumn{3}{|c|}{$\%$ discrepancy } \\
\hline & & M1 & M2 & Reg & M1 & M2 & Reg & M1 & M2 & Reg \\
\hline 32 & Lwanga Muto & 215 & 212 & 192 & 7 & 4 & -16 & 3.37 & 1.92 & -7.69 \\
\hline 33 & Kisigala & 422 & 417 & 407 & -113 & -118 & -128 & -21.12 & -22.06 & -23.93 \\
\hline 34 & Maala & 220 & 218 & 198 & -30 & -32 & -52 & -12.00 & -12.80 & -20.80 \\
\hline 35 & Kayunyu & 421 & 416 & 405 & 134 & 129 & 118 & 46.69 & 44.95 & 41.11 \\
\hline 36 & Batwala & 206 & 204 & 183 & -193 & -195 & -216 & -48.37 & -48.87 & -54.14 \\
\hline 37 & Lugumba & 658 & 650 & 651 & 212 & 204 & 205 & 47.53 & 45.74 & 45.96 \\
\hline 38 & Kisso & 466 & 460 & 452 & -244 & -250 & -258 & -34.37 & -35.21 & -36.34 \\
\hline 39 & Kalangala & 121 & 120 & 95 & 13 & 12 & -13 & 12.04 & 11.11 & -12.04 \\
\hline 40 & Kamaliba & 539 & 532 & 528 & 349 & 342 & 338 & 183.68 & 180.00 & 177.89 \\
\hline 41 & Kassa & 213 & 211 & 190 & -49 & -51 & -72 & -18.70 & -19.47 & -27.48 \\
\hline 42 & Kalokoso & 446 & 441 & 432 & 151 & 146 & 137 & 51.19 & 49.49 & 46.44 \\
\hline 43 & Kisuku & 624 & 617 & 616 & 71 & 64 & 63 & 12.84 & 11.57 & 11.39 \\
\hline 44 & Namirembe & 816 & 806 & 815 & 197 & 187 & 196 & 31.83 & 30.21 & 31.66 \\
\hline 45 & Kamuwunga & 1305 & 1289 & 1321 & -8 & -24 & 8 & -0.61 & -1.83 & 0.61 \\
\hline 46 & Ddimo & 2176 & 2149 & 2223 & 531 & 504 & 578 & 32.28 & 30.64 & 35.14 \\
\hline 47 & Lambu & 1604 & 1585 & 1631 & -800 & -819 & -773 & -33.28 & -34.07 & -32.15 \\
\hline
\end{tabular}

Reg regression

Table 4 Population estimates from analysis stratified by location

\begin{tabular}{|c|c|c|c|c|c|c|c|c|c|c|}
\hline \multirow[t]{2}{*}{ Id } & \multirow[t]{2}{*}{ Name } & \multicolumn{3}{|c|}{ Population estimates } & \multicolumn{3}{|c|}{ Discrepancy } & \multicolumn{3}{|c|}{$\%$ discrepancy } \\
\hline & & M1 & M2 & Reg & M1 & M2 & Reg & M1 & M2 & Reg \\
\hline 32 & Lwanga Muto & 229 & 223 & 234 & 21 & 15 & 26 & 10.10 & 7.21 & 12.50 \\
\hline 33 & Kisigala & 450 & 439 & 444 & -85 & -96 & -91 & -15.89 & -17.94 & -17.01 \\
\hline 34 & Maala & 235 & 229 & 240 & -15 & -21 & -10 & -6.00 & -8.40 & -4.00 \\
\hline 35 & Kayunyu & 449 & 438 & 443 & 162 & 151 & 156 & 56.45 & 52.61 & 54.36 \\
\hline 36 & Batwala & 220 & 215 & 225 & -179 & -184 & -174 & -44.86 & -46.12 & -43.61 \\
\hline 37 & Lugumba & 702 & 685 & 683 & 256 & 239 & 237 & 57.40 & 53.59 & 53.14 \\
\hline 38 & Kisso & 497 & 485 & 489 & -213 & -225 & -221 & -30.00 & -31.69 & -31.13 \\
\hline 39 & Kalangala & 108 & 111 & 19 & 0 & 3 & -89 & 0.00 & 2.78 & -82.41 \\
\hline 40 & Kamaliba & 481 & 491 & 469 & 291 & 301 & 279 & 153.16 & 158.42 & 146.84 \\
\hline 41 & Kassa & 190 & 194 & 118 & -72 & -68 & -144 & -27.48 & -25.95 & -54.96 \\
\hline 42 & Kalokoso & 398 & 407 & 369 & 103 & 112 & 74 & 34.92 & 37.97 & 25.08 \\
\hline 43 & Kisuku & 557 & 569 & 561 & 4 & 16 & 8 & 0.72 & 2.89 & 1.45 \\
\hline 44 & Namirembe & 729 & 744 & 768 & 110 & 125 & 149 & 17.77 & 20.19 & 24.07 \\
\hline 45 & Kamuwunga & 1165 & 1190 & 1295 & -148 & -123 & -18 & -11.27 & -9.37 & -1.37 \\
\hline 46 & Ddimo & 1943 & 1984 & 2235 & 298 & 339 & 590 & 18.12 & 20.61 & 35.87 \\
\hline 47 & Lambu & 1432 & 1463 & 1618 & -972 & -941 & -786 & -40.43 & -39.14 & -32.70 \\
\hline
\end{tabular}

Reg regression

an underestimate of 2002 (19.6\%). Full results are shown in Table 5.

\section{Discussion}

The simple area-based methods described here produced reasonable estimates of the overall population of our test communities, which seem to us to be sufficiently accurate for many situations, particularly where formal census data are unavailable. For example, when estimating public health needs for a group of villages, this approximate population estimate would be sufficient. The most accurate method for predicting the overall population used a simple average population density. Stratifying by location or assessed density did not improve the estimates; 
Table 5 Population estimates from analysis stratified by assessed population density

\begin{tabular}{|c|c|c|c|c|c|c|c|c|c|c|}
\hline \multirow[t]{2}{*}{ Id } & \multirow[t]{2}{*}{ Name } & \multicolumn{3}{|c|}{ Population estimates } & \multicolumn{3}{|c|}{ Discrepancies } & \multicolumn{3}{|c|}{$\%$ discrepancies } \\
\hline & & M1 & M2 & Reg & M1 & M2 & Reg & M1 & M2 & Reg \\
\hline 32 & Lwanga Muto & 143 & 125 & 182 & -65 & -83 & -26 & -31.25 & -39.90 & -12.50 \\
\hline 33 & Kisigala & 281 & 245 & 274 & -254 & -290 & -261 & -47.48 & -54.21 & -48.79 \\
\hline 34 & Maala & 261 & 267 & 206 & 11 & 17 & -44 & 4.40 & 6.80 & -17.60 \\
\hline 35 & Kayunyu & 498 & 510 & 478 & 211 & 223 & 191 & 73.52 & 77.70 & 66.55 \\
\hline 36 & Batwala & 244 & 250 & 187 & -155 & -149 & -212 & -38.85 & -37.34 & -53.13 \\
\hline 37 & Lugumba & 778 & 797 & 801 & 332 & 351 & 355 & 74.44 & 78.70 & 79.60 \\
\hline 38 & Kisso & 551 & 564 & 540 & -159 & -146 & -170 & -22.39 & -20.56 & -23.94 \\
\hline 39 & Kalangala & 81 & 71 & 141 & -27 & -37 & 33 & -25.00 & -34.26 & 30.56 \\
\hline 40 & Kamaliba & 359 & 313 & 326 & 169 & 123 & 136 & 88.95 & 64.74 & 71.58 \\
\hline 41 & Kassa & 142 & 124 & 182 & -120 & -138 & -80 & -45.80 & -52.67 & -30.53 \\
\hline 42 & Kalokoso & 297 & 260 & 285 & 2 & -35 & -10 & 0.68 & -11.86 & -3.39 \\
\hline 43 & Kisuku & 416 & 363 & 364 & -137 & -190 & -189 & -24.77 & -34.36 & -34.18 \\
\hline 44 & Namirembe & 544 & 475 & 449 & -75 & -144 & -170 & -12.12 & -23.26 & -27.46 \\
\hline 45 & Kamuwunga & 870 & 759 & 666 & -443 & -554 & -647 & -33.74 & -42.19 & -49.28 \\
\hline 46 & Ddimo & 1450 & 1265 & 1053 & -195 & -380 & -592 & -11.85 & -23.10 & -35.99 \\
\hline 47 & Lambu & 1898 & 1943 & 2087 & -506 & -461 & -317 & -21.05 & -19.18 & -13.19 \\
\hline
\end{tabular}

Reg regression

using density was particularly unsuccessful, possibly due to the difficulty in correctly categorising communities from satellite imagery. Using a regression approach did not increase accuracy. We therefore recommend the simplest, average density approach. This has the advantage of being intuitive, easy to understand and calculate, and doesn't require village-level data calculations. This method requires just one parameter and knowledge of the combined area of all the communities in which the population is to be estimated. In our data the average density parameter was 0.0287 per $\mathrm{m}^{2}$. It is an open question if this figure is applicable to other geographical regions or other types of settings, for example, mining communities or other small isolated villages. We plan to test the applicability of this method, and this average density figure, in future work using population data from surveys of other regions of East Africa.

All methods were less successful in predicting the populations of individual settlements. This is of no great surprise, given heterogeneity of densities observed; the most heavily populated FC was almost eight times as dense as the least. We would therefore not advise using these methods to predict the populations of individual communities.

For area-based methods to work there is an assumption that the villages are "similar", that is, the villages you wish to estimate the population of have a similar population density to those which provided our figure of 0.0287 . We recognise that the way we have designed this study guarantees that this requirement will be satisfied. However, we hope that this may be applicable in other communities around Lake Victoria, or fishing communities based on other lakes in East Africa. Area based methods have historically been used in urban environments $[14,15]$ or used large numbers of variables to define typologies [16]. Large amounts of the work around defining populations through remotely sensed data is in defining these typologies.

Small villages in many parts of rural Africa consist of buildings of similar type: single-storey, with little variation in building materials and construction. It is therefore surprising to find the variation in population density in FCs as we observed around the Ugandan shores of Lake Victoria. The extremes of variation may be due to the different types of FCs, some being villages that are on the lakeshore and so fishing is their main livelihood, while others may be temporary and used during certain parts of the year when the fish are in that location. The communities may be more cramped due to space limitations on islands or peninsular areas. There could also be a difference in the population makeup, as fishing communities often consist primarily of working age men and contain fewer families, resulting in varying average building occupancy rates. These would both alter the population density of the FC. We also acknowledge the difference between the date of the survey and the date the corresponding satellite image was taken; this could increase errors in our predictions if there were significant changes in the FC population between those dates. 
Following our analysis, we applied parameters from our complete dataset to data from 509 FC villages in Uganda, identified in GEP, for which we had area, but not population data. The total area was $10,946,521 \mathrm{~m}^{2}$. The average density method M1 estimated an overall population of 320,543; method M2 estimated 314023; and the regression method estimated 313,891 . Whilst it is impossible to verify the accuracy of these estimates, it is reassuring that in this setting they produced similar values and gives us hope that the simplest method is not significantly worse than a more complex approach even when estimating larger populations in a large number of villages.

The use of GEP as the source of images and the method to define area had pros and cons. It is easy to use and readily available. These are great advantages for groups in which there is little or no Geographic Information System (GIS) experience. In a very short time, it is possible to learn how to mark regions and to extract the area. Training carried out with researchers from the three countries which border Lake Victoria gave us first-hand experience that GEP could be learned in less than one hour. It was also very quick to map areas: the dataset for all villages along the Ugandan lakeshore of Lake Victoria took one person less than three to produce.

The availability and age of imagery is more of an issue. In some areas, images are plentiful and are often taken many times per year. These areas are typically areas of human activity (cities, areas of conflict, deforestation) or where natural disasters have occurred. But this is not the case in all parts of the world, particularly in more rural areas. Around Lake Victoria most images happened to be from 2012, the preceding 12 months to the majority of the population surveys. There was often only one image available. Although images were available for the majority of the area, these were not always the very high sub-metre resolution images best suited to assessing structures, but did allow the populated area to be identified.

In communities that are very stable with little change the image date is not an issue. However, in fishing communities such as those in this research, change can be very rapid, in terms of both increase and decrease in size. If the community is temporary (for instance the duration of a fishing season) then the residents may move sites frequently. There is a similarity with displaced populations, which also can change rapidly. A further limitation is that we excluded structures which were located away from the main village. This was done to ease the process of defining the boundary, and hence obtain an estimate for the village area. However, it does mean that if there are varying numbers of people living in structures away from a village, this method may not be appropriate.
The date and availability of images resulted in us having to exclude 19 villages from the analysis. In addition, the calculation of FC area from satellite images may have been inaccurate. One advantage of a simple area method is that the village areas do not have to come from satellite images; it would be possible for fieldworkers to use a handheld GPS device to define the outline of the village and thus calculate the area, removing these inaccuracies.

Our results match what is typical of other studies [7], that errors are larger for individual areas than for the population as a whole. Using a simple area method to estimate populations of groups of villages is feasible and would be a rapid and low skills way to get populations in these settings. Care would be needed to use this method to estimate populations in individual villages. Further work is needed to investigate if assigning typologies, or using more recent satellite images (or calculating area from on the ground) would improve the results.

Some progress has recently been made by organisations on population datasets such as WorldPop (Stevens FR). These datasets are still far from complete and could not be used around Lake Victoria in our target villages. There is an overlap in the work of defining population densities for different urban typologies, and it is important that data from small surveys are able to feed into the large datasets and vice versa. There is also a need for the larger datasets to be made available through simple-to-use software, and not rely so heavily on GIS skills. However it is filled, there is still a gap for a rapid, low skill method that can be applied in settings where GIS capabilities are very limited or population change was rapid.

\section{Conclusion}

Simplified methods are needed to determine the size of populations at high health risk in resource-limited settings. Satellite images may be able to help provide information in areas where access and resources to perform surveys is limited, or for which a rapid estimation is required. We have shown that it is straightforward to generate the required spatial data using widely available software such as GEP, without the need for more technical GIS skills. We have shown that using an average density of 0.0287 per $\mathrm{m}^{2}$ provides a reasonable estimate of population for a group of communities. However, care is needed when using area based methods with migratory populations, where estimates for individual communities may be associated with large errors. Overall population estimations balance out, and with further validation in more stable communities it may prove to be more viable for individual locations. Similarly using a GPS device to obtain the area of the village and multiplying by regional population densities would give a simple method where visiting the location was an option. 


\section{Authors' contributions}

CG, SK and HG designed the study. CG developed the methodology, VT and CG did the data extraction from Google Earth. VT, CH and SN contributed to the analysis. AA, RS and AG contributed survey data to the reference population database. All authors provided critical comments. All authors read and approved the final manuscript.

\section{Author details}

${ }^{1}$ London School of Hygiene and Tropical Medicine, Room G13, Keppel Street London WC1E 7HT, UK. ${ }^{2}$ MRC/UVRI Uganda Research Unit on AIDS, Entebbe, Uganda. ${ }^{3}$ Mwanza Interventions Trials Unit (MITU/NIMR), Mwanza, Tanzania.

\section{Acknowledgements}

This paper was developed in collaboration with Lake Victoria Health Research Consortium; in particular we would like to thank Pontiano Kaleebu, Andrew Abaasa, Janet Seeley, Freddie Kibengo, Asiki Gershim, Monica Kuteesa, Richard E. Sanya, and Alison Elliott (MRC/UVRI Uganda Research Unit on AIDS, Entebbe Uganda); Noah Kiwanuka, and Ali Ssetaala (UVRI/IAVI, Entebbe, Uganda); Elizabeth Bukusi and Zachary Kwena (KEMRI, Kisumu, Kenya); Saidi Kapiga, Christian Hansen, Ramadhan Hashim, Edmund Kisanga, Simon Sichalwe, and Heiner Grosskurth (MITU/UVRI, Mwanza, Tanzania); Leslie Nielsen, Jan de Bont, Anatoli Kamali, and Patricia Fast (IAVI). We gratefully acknowledge the principal investigators and field staff of surveys that provided reference data which was collected as part of other studies not linked to this paper. Data from commu nities of Koome sub-county, Mukono District, Uganda were collected as part of the Lake Victoria Island Intervention Study on Worms and Allergy-Related Diseases which is supported by the Wellcome Trust (Grant Number 095778). Data from fishing communities in Wakiso and Masaka Districts, Uganda were collected as part of epidemiological studies conducted by the MRC/UVRI Uganda Research Unit on AIDS with support from the UK Medical Research Council (MRC) and the UK Department for International Development (DFID) under the MRC/DFID Concordat agreement which is also part of the EDCTP2 program supported by the European Union.

\section{Competing interests}

The authors declare that they have no competing interests.

\section{Funding}

Funding was provided by United States Agency for International Development (Grant No. AID-OAA-A-16-00032) and Medical Research Council (GB) (Grant No. MR/K012126/1)

\section{Publisher's Note}

Springer Nature remains neutral with regard to jurisdictional claims in published maps and institutional affiliations.

Received: 27 February 2018 Accepted: 31 July 2018

Published online: 13 August 2018

\section{References}

1. National Research Council. Tools and methods for estimating populations at risk from natural disasters and complex humanitarian crises. Washington: National Academies Press; 2007

2. UN. Handbook on geographic information systems and digital mapping. New York: United Nations Department of Economic and Social Affairs Statistics Division; 2000.

3. UN. World Population Monitoring 2001: population, environment and development. New York: Department of Economic and Social Affairs; 2001.

4. ACAPS: Technical Brief: Estimation of affected population figures. 2012.

5. Sim F, McKee M. Issues in public health. London: McGraw-Hill Education; 2011.

6. Koscalova AVEU. Assessment toolkit. Geneva: Médecins Sans Frontières; 2017

7. Wu S-S, Qiu X, Wang L. Population estimation methods in GIS and remote sensing: a review. GISci Remote Sens. 2005;42:80-96.

8. Checchi F, Stewart BT, Palmer JJ, Grundy C. Validity and feasibility of a satellite imagery-based method for rapid estimation of displaced populations. Int J Health Geogr. 2013;12:4.

9. Chang AY, Parrales ME, Jimenez J, Sobieszczyk ME, Hammer SM, Copenhaver DJ, Kulkarni RP. Combining Google Earth and GIS mapping technologies in a dengue surveillance system for developing countries. Int J Health Geogr. 2009;8:49.

10. Missing Maps Project. https://www.msf.org.uk/missing-maps-project. Accessed Feb 2018

11. HOT website. https://www.hotosm.org/. Accessed Feb 2018

12. Abaasa A, Asiki G, Price MA, Ruzagira E, Kibengo F, Bahemuka U, Fast PE, Kamali A. Comparison of HIV incidence estimated in clinical trial and observational cohort settings in a high risk fishing population in Uganda: implications for sample size estimates. Vaccine. 2016;34:1778-85.

13. Sanya RE, Muhangi L, Nampijja M, Nannozi V, Nakawungu PK, Abayo E, Webb EL, Elliott AM. Schistosoma mansoni and HIV infection in a Ugandan population with high HIV and helminth prevalence. Trop Med Int Health. 2015;20:1201-8.

14. Dong P, Ramesh S, Nepali A. Evaluation of small-area population estimation using LiDAR, Landsat TM and parcel data. Int J Remote Sens. 2010;31:5571-86.

15. Li G, Weng Q. Using Landsat ETM + imagery to measure population density in Indianapolis, Indiana. USA. Photogramm Eng Remote Sens. 2005;71:947-58.

16. Harvey J. Estimating census district populations from satellite imagery: some approaches and limitations. Int J Remote Sens. 2002;23:2071-95.

Ready to submit your research? Choose BMC and benefit from

- fast, convenient online submission

- thorough peer review by experienced researchers in your field

- rapid publication on acceptance

- support for research data, including large and complex data types

- gold Open Access which fosters wider collaboration and increased citations

- maximum visibility for your research: over 100M website views per year

At BMC, research is always in progress.

Learn more biomedcentral.com/submissions 